\title{
Laser powder bed fusion of WC-reinforced Hastelloy-X composite: microstructure and mechanical properties
}

\author{
Quanquan Han ${ }^{a, b^{*}}$, Yuchen $\mathbf{G u}^{\mathrm{c}}$, Heng Gu${ }^{\mathrm{d}}$, Yingyue Yin ${ }^{\mathrm{a}, \mathrm{b}}$, Jun Song ${ }^{\mathrm{e}}$, Zhenhua \\ Zhang $^{a, b}$, Shwe Soe ${ }^{f}$
}

\begin{abstract}
aKey Laboratory of High Efficiency and Clean Mechanical Manufacture of Ministry of Education, Center for Additive Manufacturing, School of Mechanical Engineering, Shandong University, Jinan, 250061, China

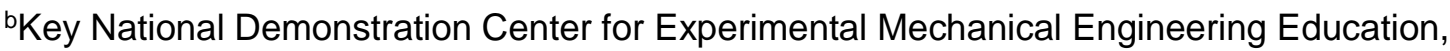
Shandong University, Jinan, 250061, China

${ }^{c}$ College of Engineering, Swansea University, Swansea, SA1 8EN, UK

${ }^{\mathrm{d} C}$ Cardiff School of Engineering, Cardiff University, Cardiff, CF24 3AA, UK

e College of Mechanical Engineering, Chongqing University, China

fDepartment of Engineering Design and Mathematics, University of the West of England, Bristol, BS16 1QY, UK
\end{abstract}

\section{Corresponding author:}

Quanquan Han: Hanquanquan@sdu.edu.cn, Tel: +86 18866805250.

\begin{abstract}
Nickel-based superalloys such as Hastelloy $X(H X)$ are widely used in gas turbine engines for their exceptional oxidation resistance and high-temperature strength. The addition of ceramic reinforcement further enhances these superalloys' mechanical performance and high-temperature properties. For this reason, this paper investigates the microstructure and mechanical property of laser powder bed fusion (LPBF) additively manufactured $\mathrm{HX}-1$ wt.\% WC (tungsten carbide) composite specimens. The results demonstrate that the LPBF-fabricated composite was observed to have several pores and microcracks, while only pores were detected in the as-fabricated pure $\mathrm{HX}$. Compared to the fabricated pure $\mathrm{HX}$, the tensile yield strength of such $\mathrm{HX}$ composite parts was increased by $13 \%$ without undue sacrifices to ductility, suggesting that the very limited number of microcracks were not sufficient to degrade the mechanical performance. The significantly increased dislocations were considered to be the primary contributor for the mechanical performance enhancement in the LPBF-fabricated composite material. The findings offer a promising pathway to employ
\end{abstract}


LPBF process to fabricate advanced microcrack-free composites with high-strength through a careful selection of ceramic reinforcement materials.

Keywords: Additive manufacturing; Laser powder bed fusion; Ceramic particles; Composites; Mechanical performance; Cracking

\section{Introduction}

Laser powder bed fusion (LPBF) is an additive manufacturing (AM) process in which metallic powder is selectively melted layer by layer using a high-power laser source [1] [2]. Nickel-based superalloys are widely used in gas turbine engine components due to these materials' unique combination of oxidation resistance, formability and mechanical properties in the temperature range of $540-1000{ }^{\circ} \mathrm{C}$ [3][4]. The benefits of using Hastelloy-X (HX) alloy over other nickel-based superalloys include superior hightemperature strength, better oxidation resistance and stress-corrosion cracking resistance. For instance, compared to Inconel 718 and Inconel 625, HX alloy is resistant to stress-strain cracking in petrochemical applications and offers good ductility, even at temperatures as high as $1200{ }^{\circ} \mathrm{C}$ [5]. The inclusion of molybdenum enables HX harder, stronger at high temperatures, and also makes it great for welding applications. Because of these reasons, $\mathrm{HX}$ alloy is widely used in gas turbine engines for combustion zone components, such as transition ducts, combustor cans and flame holders. Because of the capability and flexibility of the LPBF process, in which metallic components with complex geometries can be rapidly fabricated, the LPBF of nickelbased superalloys has recently attracted increased attention as a promising technology for the manufacture of complex structural components for the gas turbine engine sector [6][7].

Metal matrix composites (MMCs) exhibit the advantages of both matrix materials and reinforcement phases and are usable in various applications in the aerospace, defence and automotive domains [8][9]. Thus, the LPBF of MMCs has also received growing interest from both the academic and engineering communities. As a result, a wide range of reinforcement particles such as $\mathrm{Al}_{2} \mathrm{O}_{3}, \mathrm{TiC}, \mathrm{SiC}, \mathrm{WC}$ and $\mathrm{TiB}_{2}$ have been successfully employed in the LPBF of MMCs [10][11][12][13].

To date, several studies have focussed on combining the LPBF of nickel-based superalloys and MMC philosophy to additively manufacture nickel-based composites. 
However, the matrix materials employed in these studies mainly include Inconel 718 and Inconel 625. For instance, Gu et al. [14] investigated nano-TiC-reinforced Inconel 718 composites and found that refined near-spherical TiC reinforcements were evenly distributed in the matrix after the LPBF process, and much higher nanohardness values and lower wear rates could be obtained compared to the un-reinforced Inconel 718 components. Zhang et al. [15] studied the anisotropic corrosion resistance of TiC reinforced Inconel 718 composites fabricated by LPBF. They have found that the XZplane (parallel to the build direction) exhibited a weak anti-corrosion property because of the inhomogeneous microstructures, while the XY-plane (perpendicular to the build direction) was more prone to corrosion due to the irregular pores and clustered ringlike structures. Wang et al. [16] investigated the effects of carbon nanotube reinforcements on the LPBF-fabricated Inconel 625 composites. They have demonstrated that the composite exhibited a significant improvement in tensile strength with less elongation, this is because the composite offered a slightly faster cooling rate compared to the pure alloy. Rong et al. [17] investigated the gradient interface and wear performance of LPBF-fabricated Inconel 718-WC composite. Their findings revealed that the wear mechanism changed from abrasive wear to adhesive wear when the composite was subjected to dry sliding wear test. Nguyen et al. [18] studied the microstructure and mechanical properties of Inconel 718-WC composite fabricated by the LPBF process, with the size of the WC particles varying from $15 \mu \mathrm{m}$ to $53 \mu \mathrm{m}$. They found that the WC particles hindered grain growth in the solidification stage and that the intermediate layer and strong bonding between WC particles and the matrix resulted in significant improvement in both microhardness and tensile strength. Thus, there is a scope to conduct similar research investigations but in the context of HX to study whether HX composites built with the LPBF could also exhibit similar improvements.

Previous studies have reported that the strengthening effect improves with decreases in the size of the reinforcement particles [19]. However, when this size reaches the sub-micrometre and nano regions, the high surface-area-to-volume ratio, along with the strong van der Waals force, together enable the reinforcements to agglomerate and form clusters. In turn, this represents a challenge for dispersing uniformly the sub-micrometre reinforcement particles amongst the metallic powder. One common method for dispersing such sub-micrometre reinforcement particles is 
the high-energy ball-milling process, in which a certain number of very hard milling balls are used to disperse the mixed powders for a few hours [20][21]. The high energy that is generated during the ball-milling process, however, can damage the crystal structure of the metallic powder in addition to the chemical contamination that generally takes place after a long milling time.

In this context, the aim of this study is to synthesise $\mathrm{HX}$ with $1 \mathrm{wt}$ \% sub-micrometre WC feedstock using a dual asymmetric high-speed mixing technique to uniformly disperse the WC reinforcement without damaging the crystal structure of the HX. The WC sub-micrometre ceramic particles were selected because WC could retain its room temperature hardness up to $1400{ }^{\circ} \mathrm{C}$; it also exhibits excellent wear resistance, corrosion resistance and chemical stability with no phase changes during heating and cooling [22][23][24]. The addition of WC particles is expected to result in the enhancement in tensile strength and also improve the composite's high-temperature properties, which offers great potential for advanced $\mathrm{HX}$ composite in the applications of gas turbine engines. Another novelty of this work is its exploration on the microcracking formation mechanism for LPBF-fabricated composites.

\section{Materials and experimental procedure}

\subsection{Feedstock powder materials}

The commercial HX powder used in this study was provided by Sandvik Osprey (Neath, UK) through gas atomisation with nitrogen. Using laser diffraction analysis, the $\mathrm{HX}$ powder was measured to have an average particle size of $34 \mu \mathrm{m}$, with a spherical morphology (Fig. 1a/c). The alloying composition (wt.\%) of the HX powder is shown in Table 1.

Table 1.

Alloying composition of the HX powder.

\begin{tabular}{|c|c|c|c|c|c|c|c|c|c|c|}
\hline Element & Cr & Fe & Mo & Co & W & Si & Ti & Al & C & Ni \\
\hline wt. \% & 21.4 & 18.6 & 9 & 1.49 & 0.58 & 0.15 & 0.01 & 0.04 & 0.014 & Bal. \\
\hline
\end{tabular}

The sub-micrometre WC reinforcement particles (150-200 nm) were acquired from Sigma Aldrich (UK). As mentioned earlier, due to the high surface-area to volume ratio, such particles tend to agglomerate to form clusters (Fig. 1b). 


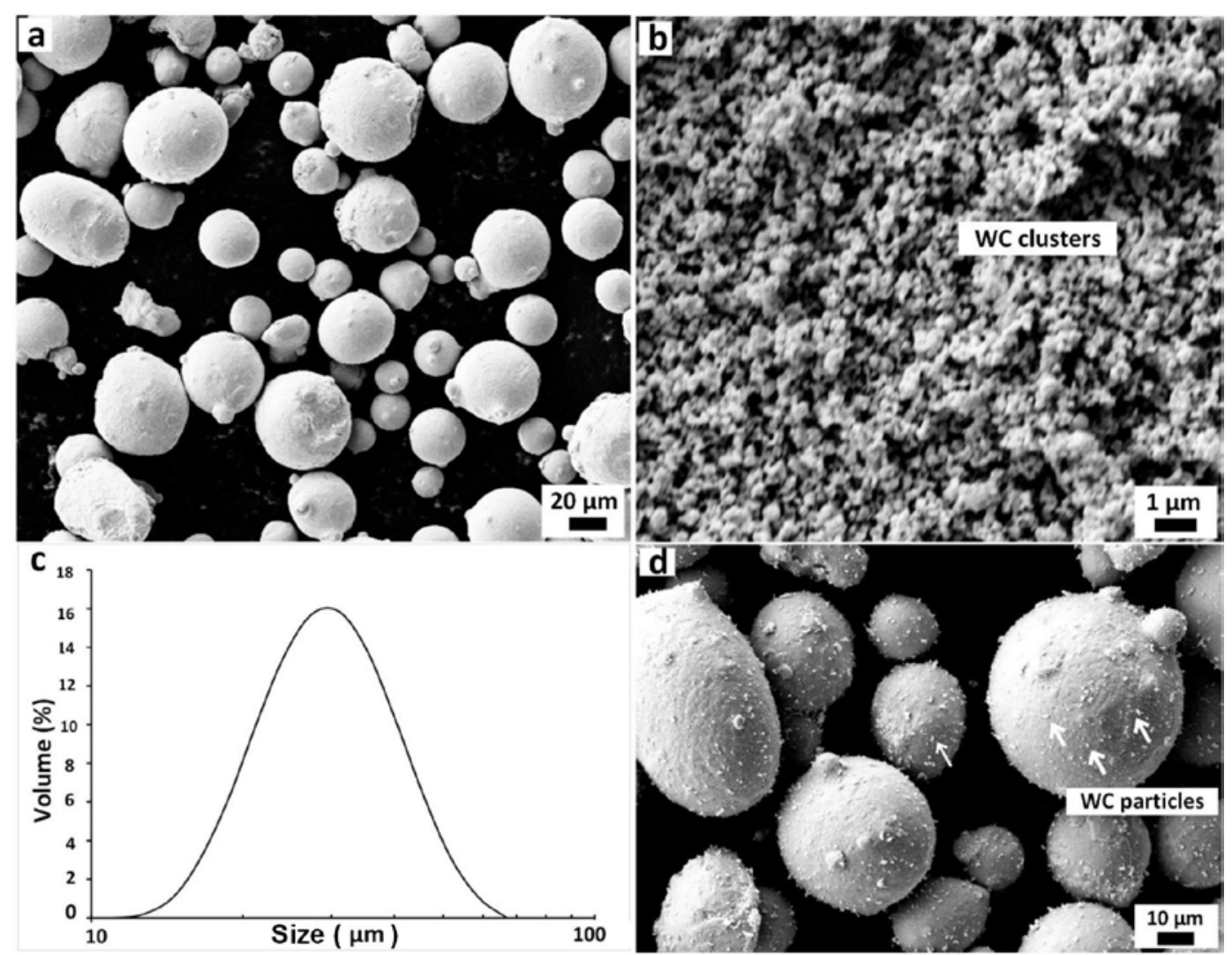

Fig. 1. Feedstock powder materials used in this study: (a) original Hastelloy $X$ powder; (b) agglomerated WC particles; (c) particle size distribution of Hastelloy X powder; (d) highspeed mixed Hastelloy X with 1 wt.\% WC composite powder.

A commercial high-speed mixer (SpeedMixer, DAC 800.1 FVZ, Hauschild, Germany) with a maximum speed of 2,000 rpm was used to synthesise the $\mathrm{HX}-1 \mathrm{wt} . \%$ WC composite feedstock. The mixer employs a dual asymmetric technology to disperse the WC particles. The mixing parameters include a mixing speed of 1,200 rpm, with 5 minutes of mixing time. Fig. 1d shows the synthesised HX-WC composite feedstock. The WC clusters were successfully broken up and dispersed on the surface of the HX powder, which suggests that the high-speed mixing process separated the clusters by overcoming the van der Waals adhesive force.

\subsection{Specimens and selective laser melting}

A Renishaw AM250 (Renishaw Plc, UK) system was employed in this study to fabricate both the tensile and lattice specimens. Based on preliminary experiments, the optimum primary parameters for building the HX and HX-WC composite samples were determined to be as follows: laser power $=200 \mathrm{~W}$; layer thickness $=40 \mu \mathrm{m}$; hatch spacing $=100 \mu \mathrm{m}$; scanning speed $=600 \mathrm{~mm} / \mathrm{s}$ [25]. The rotation angle was set to $67^{\circ}$ between any two adjacent layers to minimise the porosity of the fabricated samples 
(Fig. 2a). The dimensions of the tensile specimens were determined based on the ASTM-E8/E8M-13a guidelines (Fig. 2b). The tensile specimens are used to examine the effects of WC reinforcement on the mechanical properties of the LPBF-fabricated composites. It should be noted that the laser beam is running in pulsed mode with a point distance of $60 \mu \mathrm{m}$ to manufacture samples rather than in continuous mode (Fig. 2c).

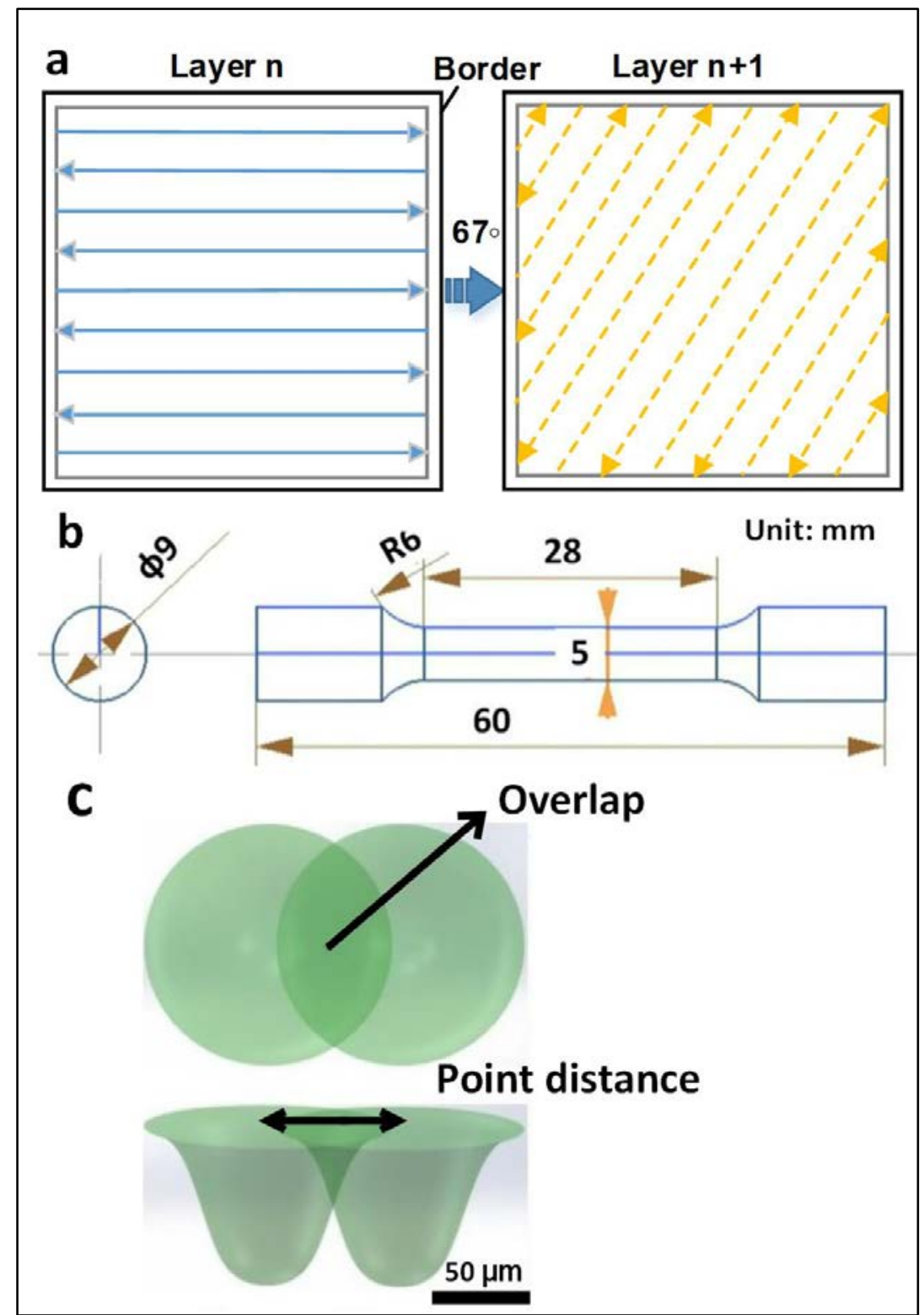

Fig. 2. Schematic of the employed laser melting strategy and samples: (a) the laser melting strategy; (b) the dimensions of the tensile specimens; (c) the working mode of the employed pulsed laser beam.

\subsection{Material characterisation}

Both pure $\mathrm{HX}$ and HX-WC composite samples were vertically sectioned, ground and polished prior to inspection via optical microscopy (OM) and scanning electron 
microscopy (SEM) similarly to the procedure described in [26]. The polished samples were electrochemically etched using oxalic acid to reveal the microstructure and molten pools that formed. Backscattered electron (BSD) SEM mode was used to investigate the distribution of the WC particles and energy-dispersive X-ray spectroscopy (EDS) mapping was employed to examine the chemical composition of the as-fabricated specimens. Electron backscatter diffraction (EBSD) analysis was performed using a high resolution Jeol 7800F FEG-SEM equipped with an Oxford Instruments AZtec EBSD system, to study the microstructure evolution and grain crystallographic orientations. Uniaxial tensile testing was performed using a Zwick/Roell tester (maximum load of $100 \mathrm{kN}$ ) with a strain rate of $1.33 \times 10^{-3} \mathrm{~s}^{-1}$ at room temperature. The engineering tensile stress-strain curves were then obtained on the basis of two specimens for each material.

\section{Results}

\subsection{Surface finish}

Fig. 3 shows the surface finish of the as-fabricated pure HX and HX-WC composite samples. Both balling and spattering surface defects were observed on the top surface of the two samples (Fig. 3a-b). The balling defects were more likely to have been formed in the 'valley zone', where two adjacent tracks overlap. These defects typically occur because, during the solidification stage, the thermal gradient and surface tension gradient enabled the formation of unstable molten tracks. As a result, the molten materials tend to reduce the surface energy and to form balls on the track edge [27]. Balling is detrimental to surface quality and can be controlled by optimising the process parameters. 

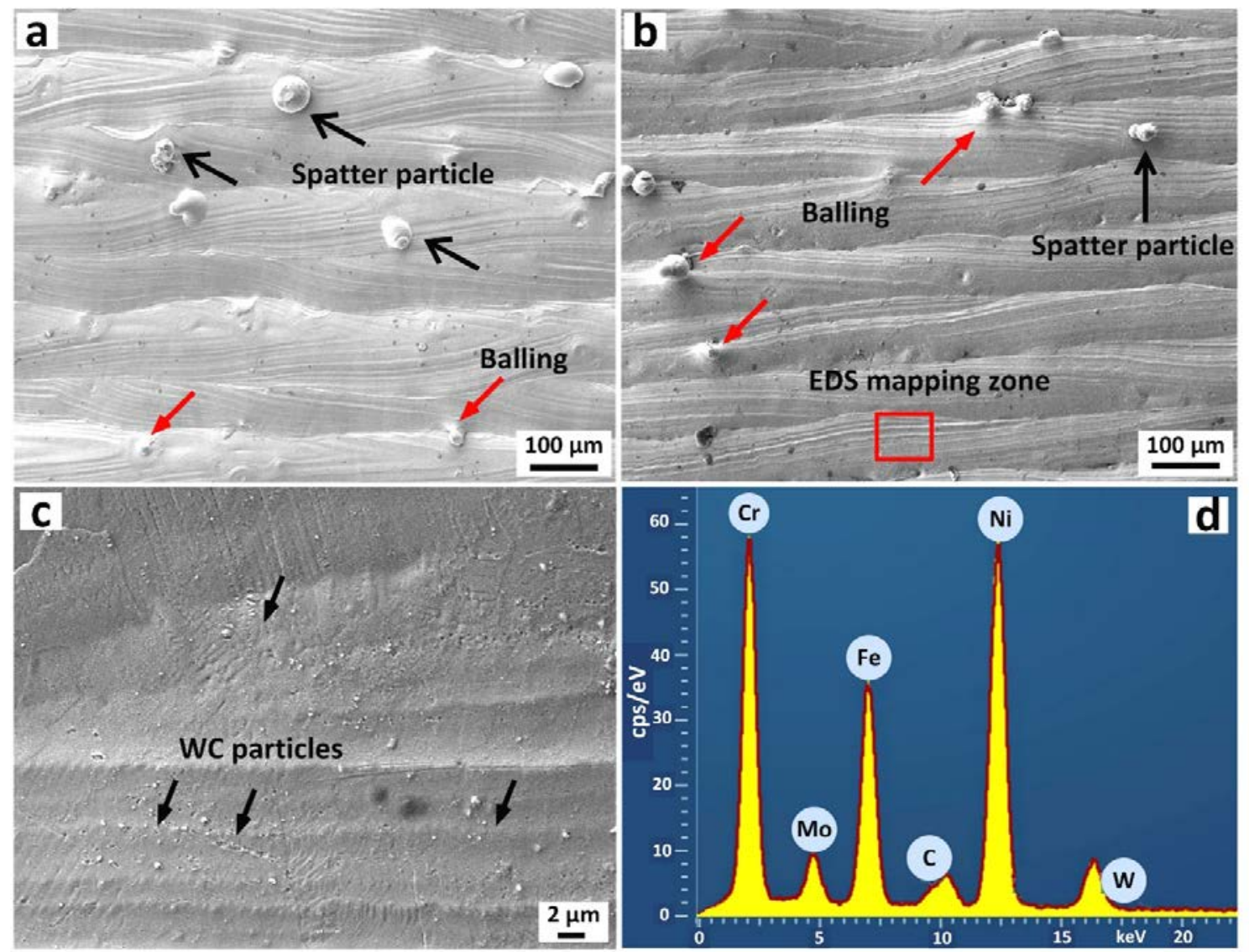

Fig. 3. Surface finish of as-fabricated samples: (a) pure HX; (b) $H X-1$ wt.\% WC composite; (c)-(d) EDS spectrum taken from the zone in (b) showing the WC particles on the sample surface.

In addition to balling defects, spattered particles were also observed on the top surface and were distributed more randomly [28]. These spattered particles may be classified into two types based on particle size: (1) large spatters with sizes greater than $10 \mu \mathrm{m}$, and (2) small spatters below $10 \mu \mathrm{m}$. The mechanism of spatter formation has already been investigated in several previous reports (see [29] [30] [31]) and will not be discussed in the present work. Fig. $3 \mathrm{c}$ and d show the EDS spectrum taken from the measured area referenced in Fig. 3b. In addition to peaks of the primary alloying elements (i.e. Fe, Ni and Mo), strong $\mathrm{W}$ peaks were also detected, implying the existence of WC particles on the surface of the HX-WC composite samples. The Marangoni convection drove the migration of WC particles in molten pools; the WC particles were dispersed and the majority stayed inside the molten pools, while the rest were pushed out and stayed on the surface after the solidification. Another factors that caused the WC particles motion to the surface zone include the recoil pressure induced by the evaporation of the boiled molten $\mathrm{HX}$ material [32] and the poor wettability of WC ceramic particles so that some WC particles remained on the surface 
of the melt pools after rapid solidification. It should be noted that the poor wetting between the WC particles and the molten HX material may result in interfacial defects in the fabricated composite components.

\subsection{Microstructure analysis}

Fig. 4 shows the microstructure of the vertical sections (parallel to the build direction) for both pure HX and HX-WC composite under optical microscopy (OM). Both samples were measured to have a relative density greater than $99.3 \%$, on the basis of the Archimedes method. A few open pores smaller than $40 \mu \mathrm{m}$ were observed on the pure HX (Fig. 4a), while several extra microcracks were found to have formed on the composite sample (Fig. 4c). The factors that could cause porosity include a lack of fusion [10], the inclusion of oxide [33], internal gas porosity from the feedstock [34] and gas entrapment during laser melting [35]. When the molten pools for the etched samples were compared, pure HX visibly exhibited much narrower and deeper molten pools compared to the composite, even though the samples were manufactured under the same conditions (Fig. $4 \mathrm{~b}$ and $\mathrm{d}$ ). This outcome may be explained by the addition of 1 wt.\% sub-micrometre WC particles, which altered the material thermal conductivity and regulated laser absorption. Many studies have demonstrated that the composite powder feedstock witnesses a significant increase in laser absorption due to the increase in surface roughness [36][37][38], while the effective thermal conductivity reduces because of the interfacial thermal resistance compared to the matrix alloys [39][40]. The changes in thermo-physical properties could further affect the size of melted zone and heat affected zone. In addition, the melting dynamics is also altered due to the changes in viscosity and weldability after the addition of WC particles, which also changed the molten pool shapes of the as-fabricated composite. In addition to the open pores that were observed, several microcracks along the build direction (referred to and annotated as BD in Fig. 4 and following figures) were also detected in the composite specimen (Fig. 4d). The possible mechanisms for microcrack formation will be discussed in the next subsection. 


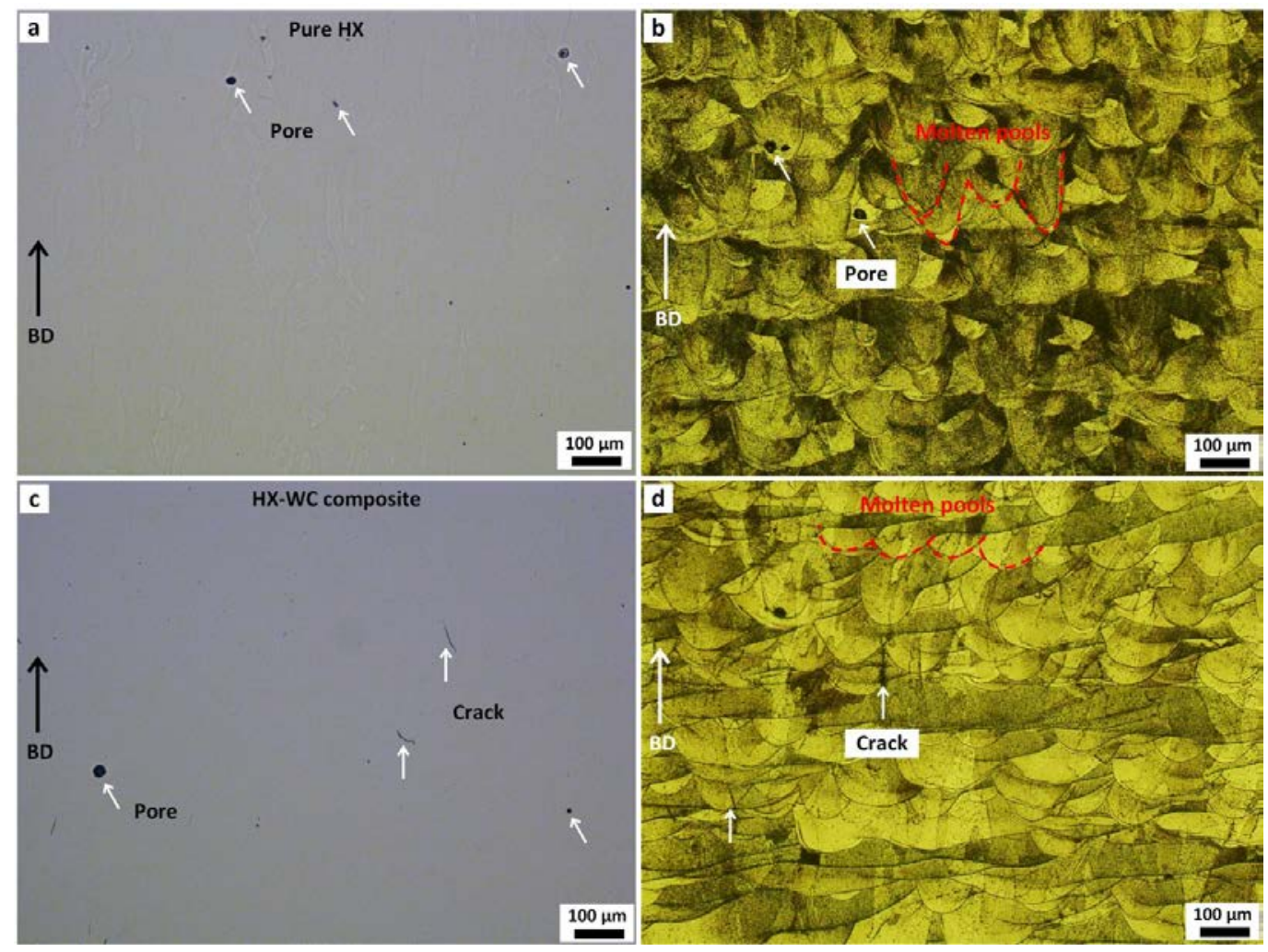

Fig. 4. OM images showing the microstructure of vertical sections of (a)-(b) as-fabricated pure HX; (c)-(d) as-fabricated composite specimen.

Fig. 5 shows the microstructure of the two samples under SEM examination. For both samples, fine cellular and columnar solidification structures were observed to have formed. The size of cellular structures and grains orientation are known to be linked to solidification conditions such as cooling rate and thermal gradient [41] [42]. One should note that the columnar grains grew across the fusion boundaries (Fig. 5a), indicating that the grains grew along the positive thermal gradient. The dendritic spacing was not found to differ significantly between the pure HX and composite specimens. The microcracks that formed in the composite were measured to vary from several to a hundred micrometres, which implies that the cracks propagated to a few layers along the build direction. In addition, the microcracks tended to form at the grain boundaries, which suggests that they were intergranular cracks. 

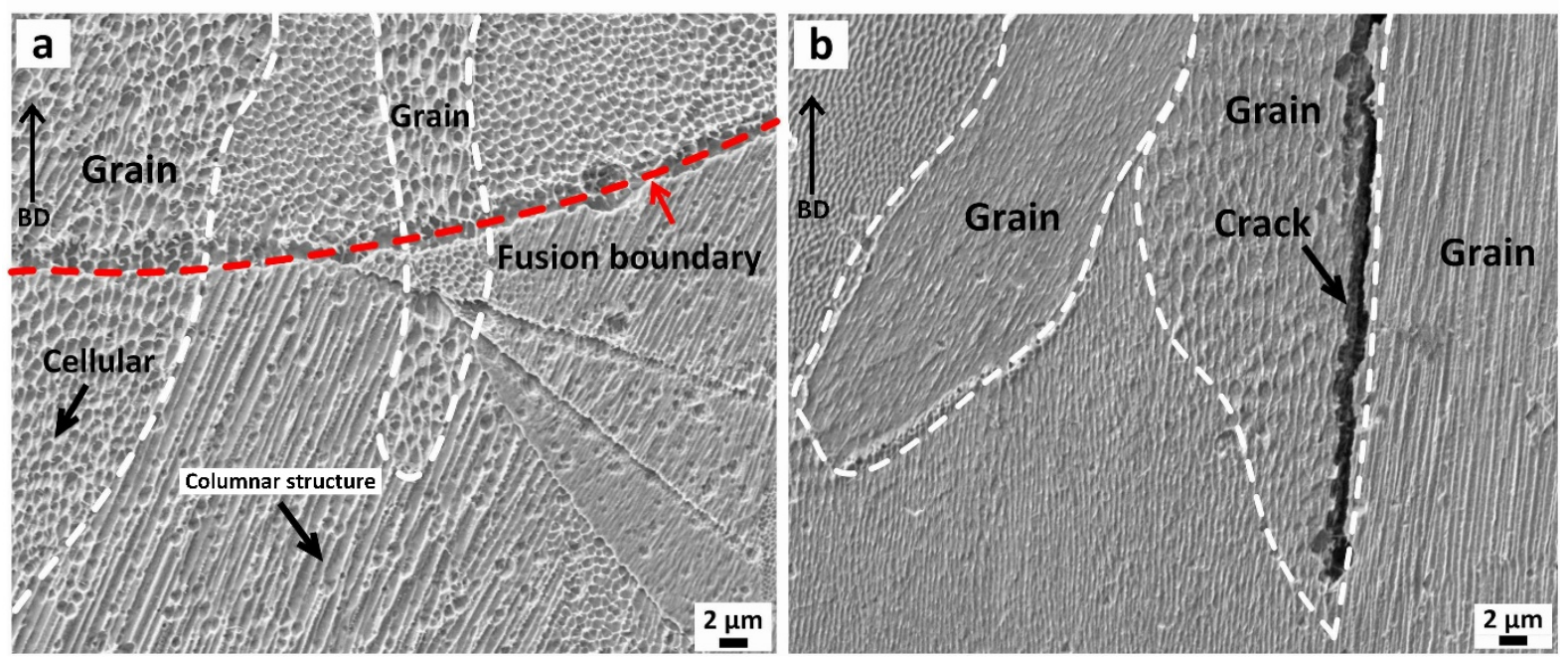

Fig. 5. SEM images showing the microstructure of as-fabricated samples: (a) pure HX with typical solidification structure formed; (b) microcrack formed in the composite specimen.

It should be noted that microcracks were not detected in the fabricated pure $\mathrm{HX}$ alloy, but were observed in the composite samples, suggesting that the added submicrometre WC particles enabled the grain boundaries more susceptible to hot cracking. Considering the coefficient of thermal expansion (CTE) of HX alloy and WC ceramic material, which are $15 \mu \mathrm{m} \cdot \mathrm{m}^{-1} \cdot \mathrm{K}^{-1}$ and $5.5 \mu \mathrm{m} \cdot \mathrm{m}^{-1} \cdot \mathrm{K}^{-1}$, respectively, the difference in CTE thus was a possible contributor to the microcracks formation. Furthermore, the microcracks could be easily generated if the sub-micrometre WC particles agglomerated at the grain boundaries during the rapid solidification process. 


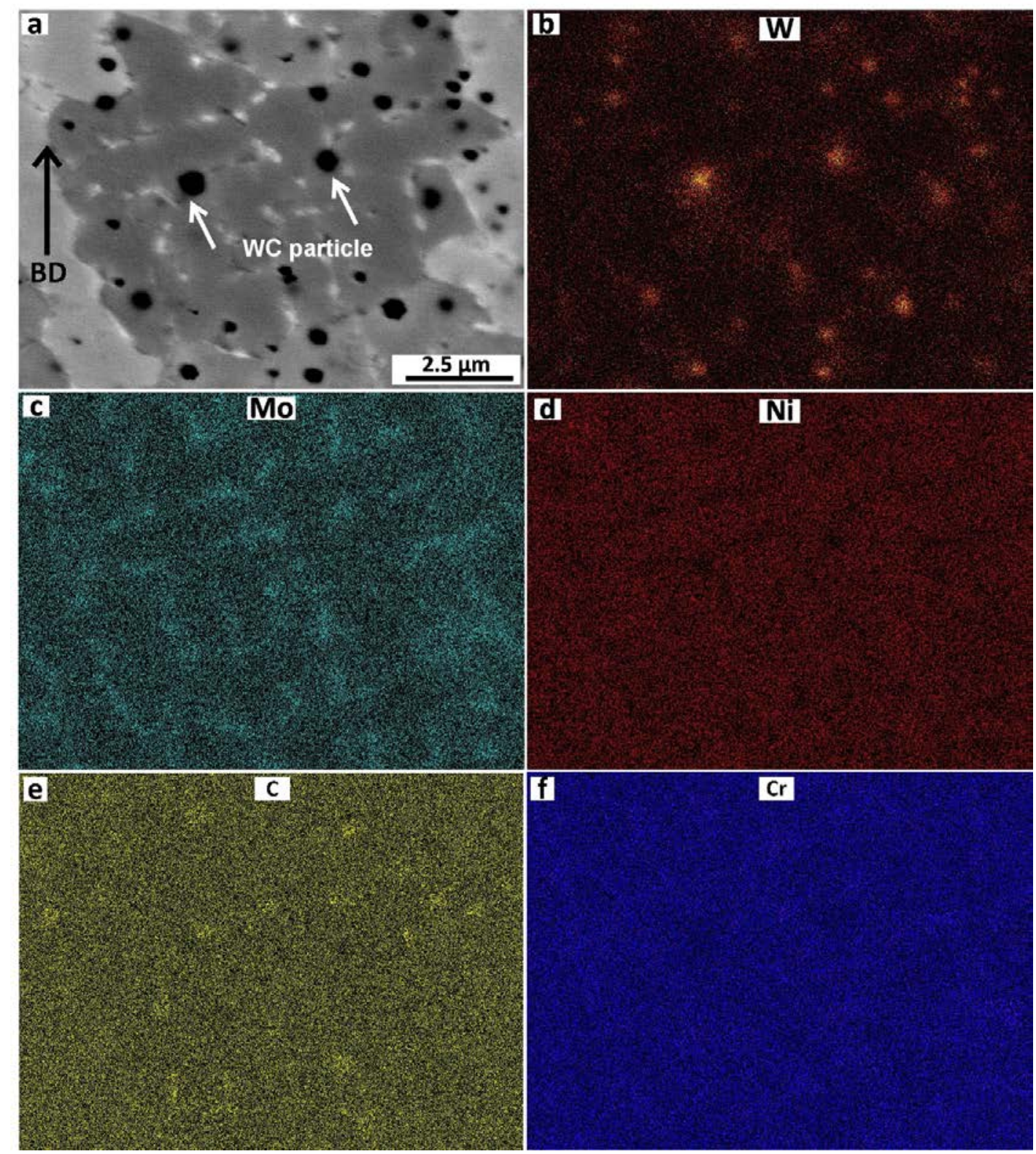

Fig. 6. The uniform distribution of WC particles in HX matrix: (a) high magnification SEM image of the composite; (b)-(f) EDS mapping for the area shown in Fig. 6a.

A high-magnification BSD-SEM micrograph reveals the distribution of WC particles in the HX matrix (Fig. 6a); considering the CTE difference between WC particles and the $\mathrm{HX}$ matrix, a higher dislocation density was expected in the as-fabricated composite to enhance the mechanical strength, which will be investigated in the next subsection. The BSD-SEM micrograph also clearly shows that the majority of the WC particles were uniformly distributed in the HX matrix, as confirmed by the EDS mapping analysis (Fig. 6b-f). This may be due to the fact that during the rapid melting and solidification stage, the Marangoni convection in the molten pool could have contributed to break the WC clusters and disperse the fine particles, rather than further agglomerating them together. The Marangoni convection is known to be derived from 
the molten pool surface's tension gradients; the molten fluid tends to flow from hot areas to relatively cool areas in the molten pool [43][44]. The EDS mapping analysis also reveals that segregation occurred within the LPBF process and the segregated phase was found to be Mo-enrichment around the fine cellular structure (Fig. 6c).

Fig. 7 shows the EBSD micrographs for both pure HX and composite materials. These images are useful for the investigation of the added WC particles in changing the microstructure of $\mathrm{HX}-\mathrm{WC}$ composites. Both materials offered random grain orientations but the grain size and morphology differed in the two samples after the LPBF process (Fig. 7a/c). In addition, a large number of columnar grains formed in both materials, suggesting that the added WC particles may not be an effective nucleating agent to promote the heterogeneous nucleation and formation of finer grains in the fabricated HX-WC composite. However, the composite exhibited a significant increase in LAGBs compared to the pure HX material on the basis of the EBSD image quality maps (Fig. 7b/d). The LAGBs or subgrain boundaries are those grains with a misorientation less than 10 degrees and are generally composed of an array of dislocations. 


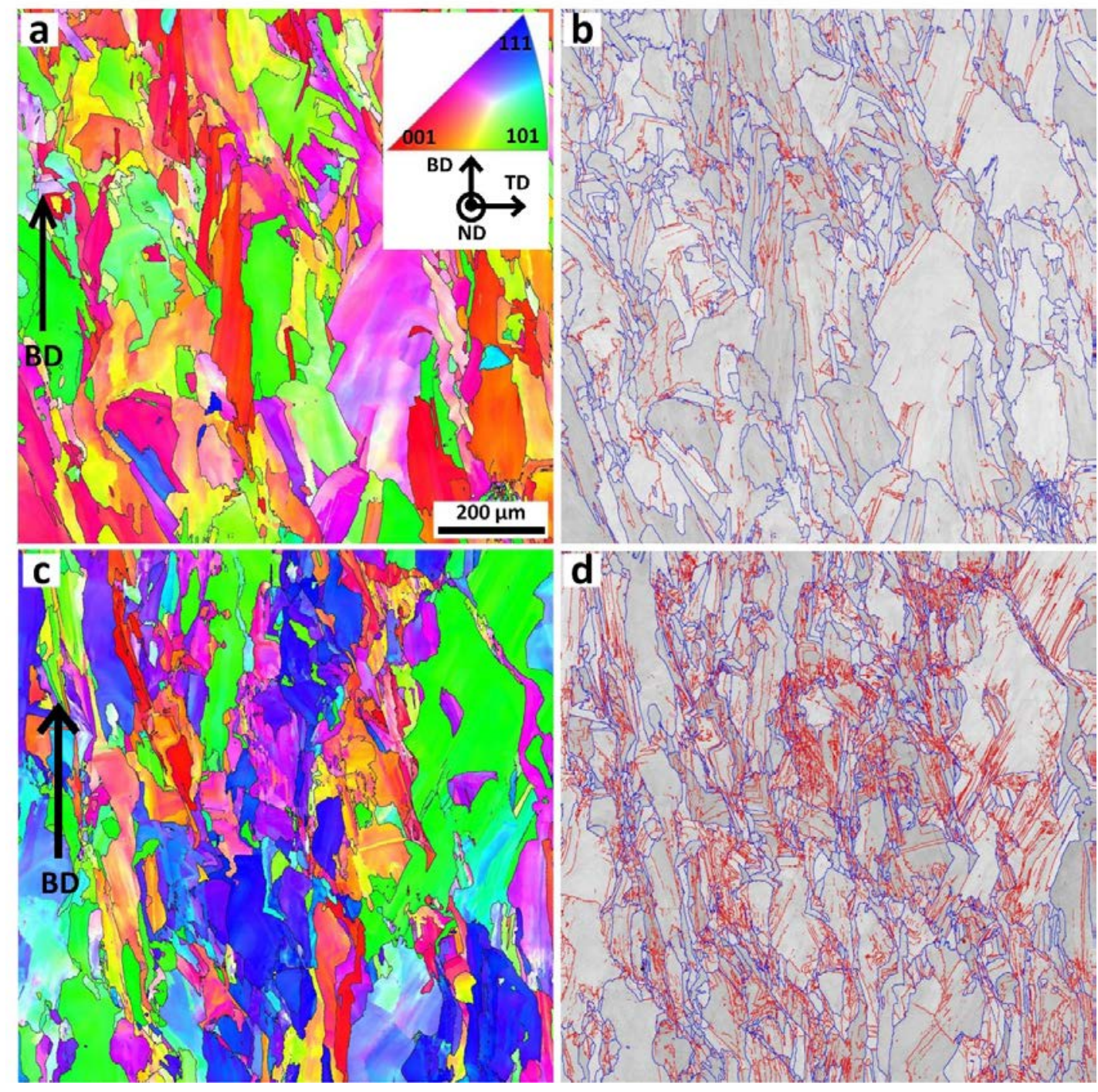

Fig. 7. EBSD images of the fabricated samples: (a) inverse-pole figure (IPF) map of the pure HX; (b) EBSD image quality (IQ) map with high-angle grain boundaries (HAGBs) and lowangle grain boundaries (LAGBs) superimposed for the pure HX; (c) IPF map of the composite; (d) IQ map with HAGBs and LAGBs superimposed for the composite. HAGBs $\left(>10^{\circ}\right)$ are coloured blue and LAGBs $\left(2^{\circ}-10^{\circ}\right)$ are red.

As mentioned before, the difference in CTE between the HX matrix and WC particles was a possible contributor for the microcracks formation in the fabricated HXWC composites. On the other hand, such CTE mismatch was the primary contributor to the significant increase in dislocations for the composite. Previous studies have suggested that the contribution of CTE mismatch strengthening is significant in LPBFfabricated composites because the CTE difference between the matrix and ceramic particles increases with temperature [45][46]. The entanglements of dislocation lines were anticipated to hinder the dislocations' motion and could have enhanced the mechanical strength of the fabricated composite material. It can be anticipated that the 
LPBF-fabricated advanced composites with high-strength and without microcracking defect could be achieved through a careful selection of ceramic reinforcements.

\subsection{Mechanical behaviour}

Fig. 8 shows the tensile test results of both the as-fabricated pure HX and HX-WC composite specimens and their fracture surfaces. The two specimens (hereafter referred to as $\mathrm{HX}-\mathrm{a}$ and $\mathrm{HX}-\mathrm{b}$ ) were used to obtain the stress-strain curves for pure $\mathrm{HX}$, while HX-WC-a and HX-WC-b were used for the composite material. The tensile performances for both cases were found to be very consistent. For pure $\mathrm{HX}$, the yield strength and elongation were found to be $590 \pm 5 \mathrm{MPa}$ and $37 \pm 2 \%$, respectively. Compared to pure $\mathrm{HX}$, the composite specimens were found to have a roughly 80 $\mathrm{MPa}$ increase in yield strength, while no significant reduction was found in elongation; an average elongation value of $32 \%$ was determined. The $13 \%$ enhancement in yield strength may be explained by the addition of the $1 \mathrm{wt}$ \% sub-micrometre WC particles. It should be noted that the limited number of microcracks that formed in the composite material were not found to have significantly degraded the tensile strength. However, these may reduce the fatigue performance of the LPBF-fabricated composite specimens.

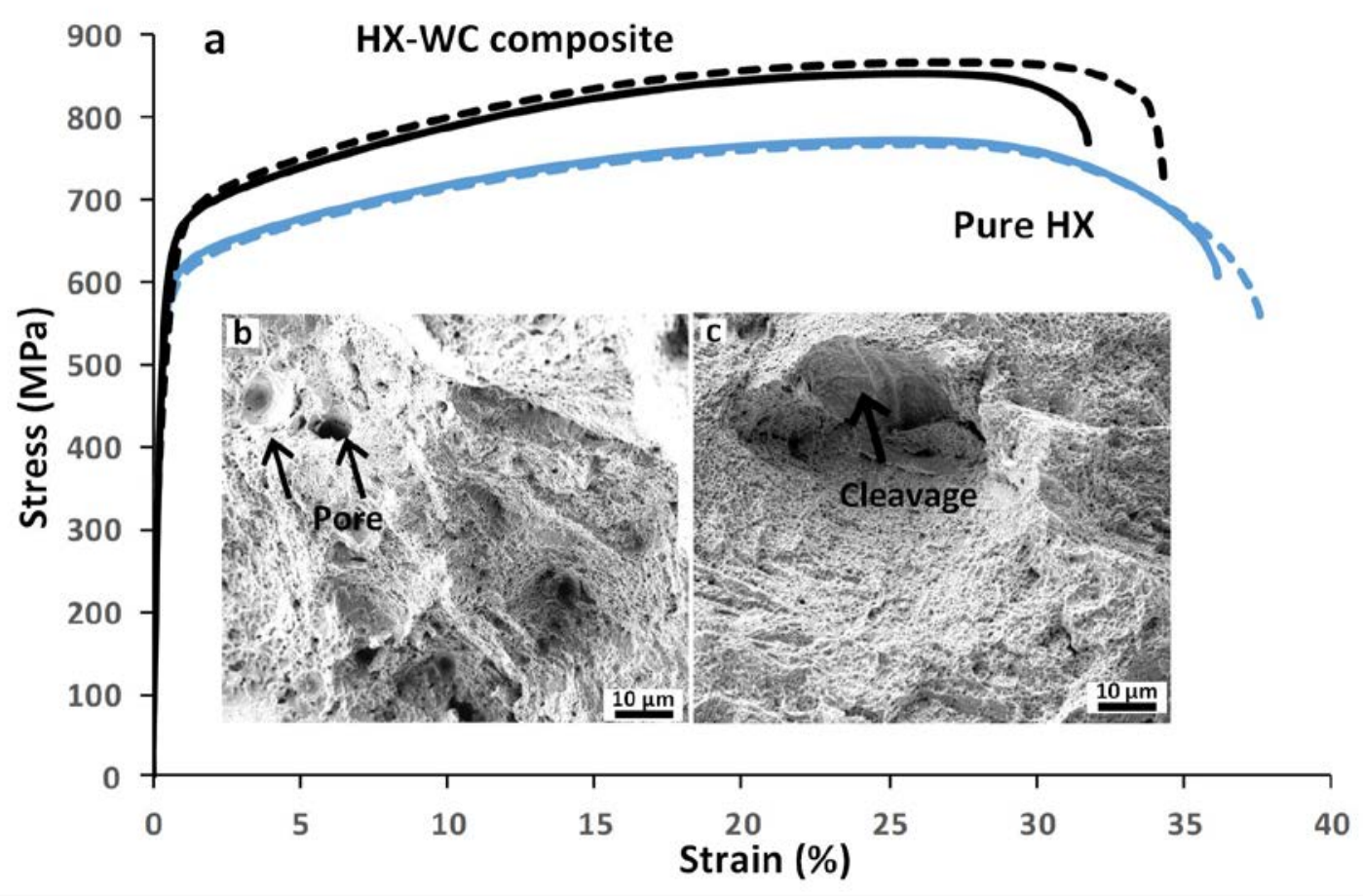

Fig. 8. Tensile performance of as-fabricated samples: (a) tensile stress-strain curves of asfabricated pure HX and HX-WC composite; (b) fracture surface for pure HX; (c) fracture surface for the composite. 
The fracture surfaces of both pure HX and HX-WC composite samples after tensile testing are shown in Fig. 8b-c. Both samples exhibited significant necking phenomena which is consistent with the fact that similar elongation values were found. Compared to the open pores observed in the as-fabricated samples, both the microcracks and pores were further opened under uniaxial loading. The limited number of cleavage-like fracture features and the large number of dimples observed imply a dominance of ductile fracture behaviour for both materials. This type of fracture behaviour in the present study was different from that found in the authors' previous study [6], in which some elongated grains with a dendritic structure were observed in the fracture surface. This behaviour may be attributable to the difference in the build and loading directions. In particular, the build direction was parallel to the uniaxial loading direction in the previous work [6], while the two directions were perpendicular in the present work. Another possible factor could be the slight difference in alloying composition between the used $\mathrm{HX}$ materials.

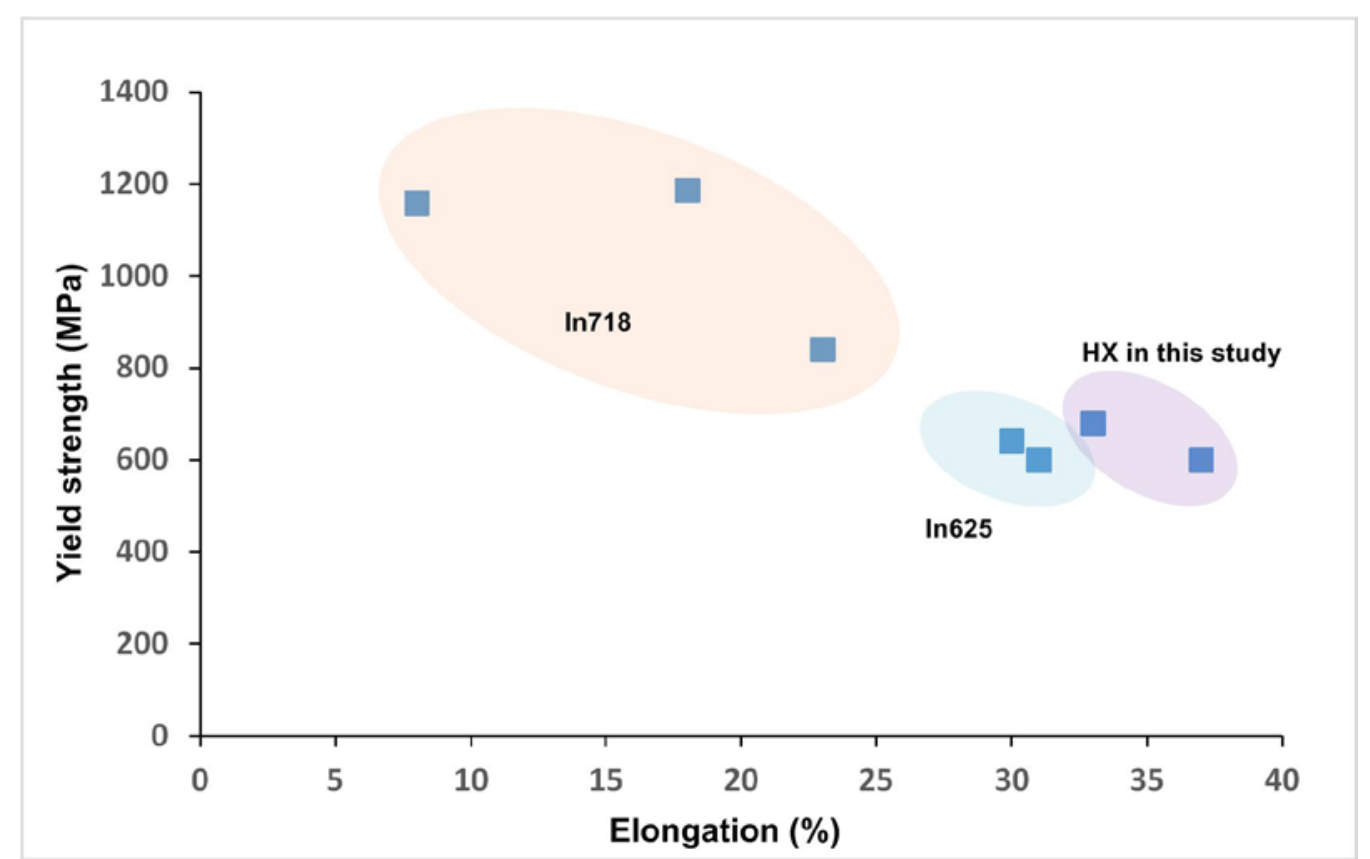

Fig. 9. 'Yield strength' versus 'elongation to failure' values between $\mathrm{HX}$ composites and typical Inconel alloys [47][48][49][50][16].

The 'yield strength' versus 'elongation to failure' values for $\mathrm{HX}$ composites materials reported in the present study compared to the typical Inconel alloys from the literature are shown in Fig. 9. The LPBF-fabricated Inconel 718 alloy exhibited over $500 \mathrm{MPa}$ increase in yield strength but also witnessed over 15\% reduction in elongation to failure compared to the HX composites. The as-fabricated Inconel 625 
alloy was found to have comparative yield strength values, but the elongation values were around $5 \%$ lower compared to the HX composites. The differences in mechanical performance between $\mathrm{HX}$ composites and typical Inconel alloys indicate that the chemical composition plays a significant role in determining the mechanical behaviour of LPBF-fabricated nickel-based superalloys. As mentioned before, the addition of molybdenum in $\mathrm{HX}$ alloy enables this material harder, stronger at high temperatures, and also makes it superior for welding applications compared to Inconel alloys.

The underlying microstructure mechanisms between $\mathrm{HX}$ and typical Inconel alloys may be attributable to the different precipitation strengthening phases induced by the alloying elements. For instance, the addition of $\mathrm{Al}$ and $\mathrm{Ti}$ alloying elements in Inconel 718 contributes to the formation of gamma prime phase, which significantly enhances the strength of LPBF-fabricated Inconel 718. The added Nb alloying element enables the formation of gamma double prime in Inconel 625 to strengthen this superalloy at lower temperatures (below $700^{\circ} \mathrm{C}$ ). Compared to Inconel 718 and Inconel 625, HX alloy is a solid-solution strengthening superalloy, which is composed of gamma phase. The addition of sub-micrometre WC ceramic particles could enhance the strength of LPBF-fabricated HX composites through the CTE mismatch strengthening and grain refinement strengthening mechanisms.

\section{Discussion}

The experimental results of this study demonstrate that the added $1 \mathrm{wt} \%$ submicrometre WC particles enabled a roughly $13 \%$ improvement in tensile yield strength on the basis of the tensile specimens. The high-speed mixing process was confirmed in this study to be capable of evenly dispersing WC particles on the surface of $\mathrm{HX}$ particles. Following the completion of the LPBF process, the majority of the WC particles were observed to be uniformly distributed in the HX-austenite matrix. The underlying microstructure evolution mainly include ceramic reinforcements strengthening and microcracking formation mechanisms induced by ceramic particles agglomeration. Fig. 10a shows a schematic of the potential strengthening mechanism. The primary strengthening mechanism could be the CTE mismatch strengthening that occurs in the composites, where the dislocation density and residual stresses increase due to the mismatch of CTE between the sub-micrometre WC and HX alloy. This strengthening mechanism has been confirmed by our EBSD examination that a much 
higher dislocation density was detected in the fabricated composite samples compared to the pure HX alloy. However, during the rapid solidification stage in LPBF process, the relatively fine WC particles (150-200 nm) may not act as nucleation sites to promote heterogeneous nucleation and enable the formation of fine grains, because a large number of columnar grains also formed in the as-fabricated composite samples. This may be explained by the high lattice disregistry value between WC and $\mathrm{Ni}$ (the matrix in HX alloy) crystals. The degree of potency of the nucleation catalysts could be explained on the basis of the disregistry between the lattice parameters of the substrate and the nucleating phase via the planar crystallographic disregistry theory [51].

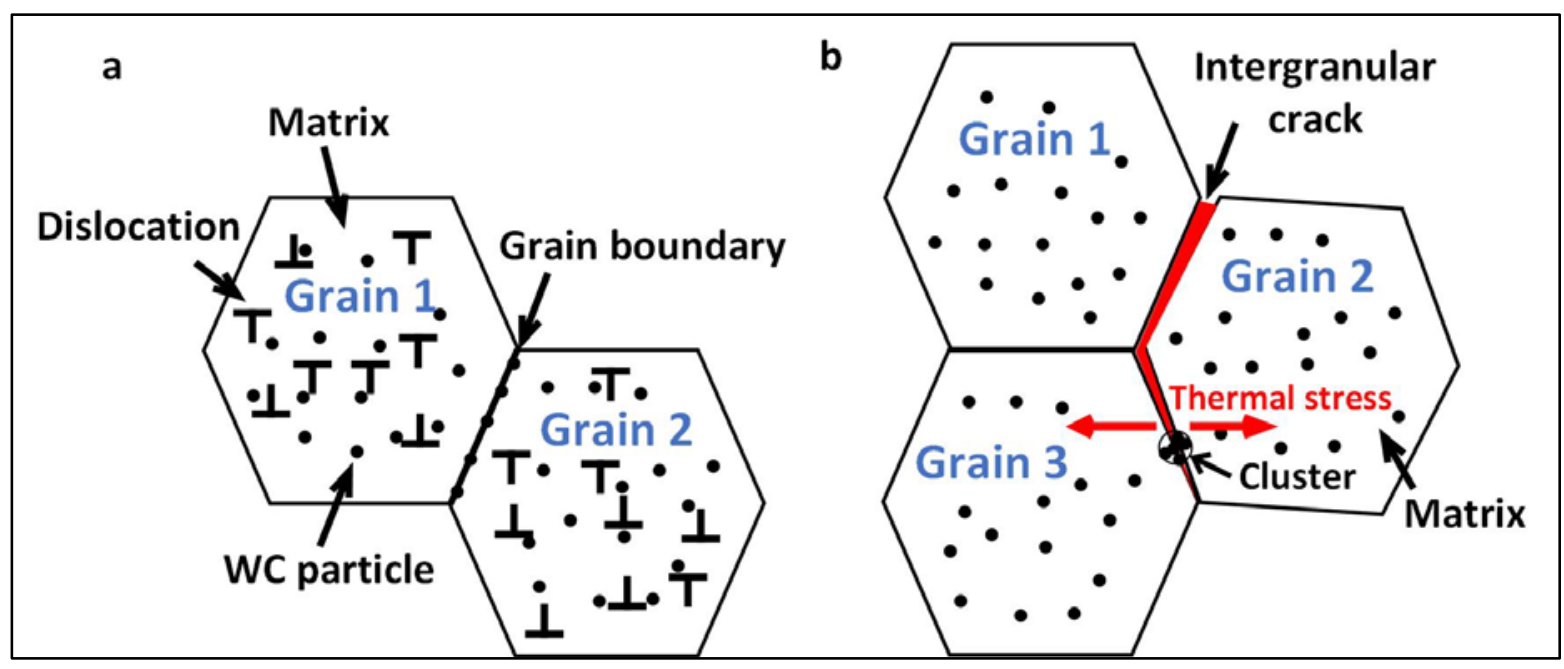

Fig. 10. Schematic of (a) the enhanced dislocation density mechanism and (b) intergranular microcrack formation.

This study has confirmed that the addition of $1 \mathrm{wt} . \% \mathrm{WC}$ particles could contribute to a remarkable enhancement in tensile strength of the as-fabricated composite at room temperature. Considering the high-temperature applications of the $\mathrm{HX}$ superalloy and the superior hardness, high melting point of WC ceramic particles, the SLM-fabricated HX-WC composite is expected to enable a significant improvement in mechanical performance at high temperatures compared to the pure HX alloy, which will be investigated in future work.

The introduction of sub-micrometre WC particles, in addition to enhancing mechanical strength, was also found to result in microcrack formation at the grain boundaries, while those microcracks were not detected in the pure HX after the LPBF process. Fig. 10b shows a possible microcrack formation mechanism in the LPBFfabricated HX-WC composites. Because of the size of the WC particles (150-200 nm), 
when a few particles agglomerated on the grain boundaries, those boundaries may tend to become susceptible to hot cracking. Previous studies have reported that Morich and $\mathrm{Cr}$-rich carbides segregate at grain boundaries in the additive manufacturing of HX alloy [52][53]. The Mo-rich carbides were also detected in the fabricated composite sample based on our EDS mapping. The carbides, together with WC clusters, may result in microcrack formation when the accumulated thermal residual stress is sufficient to pull apart two grains, thus forming microcracks. Such microcracks could then propagate along the build direction and grain boundaries and extend to a few layers in length.

\section{Conclusion}

This study has confirmed that the addition of sub-micrometre WC particles to Hastelloy- $X(H X)$ powder could lead to improved tensile strength when manufacturing HX superalloy specimens using the laser powder bed fusion (LPBF) process. This result was derived by investigating for the first time the microstructure and mechanical behaviour of Hastelloy X-1 wt.\% WC composite fabricated via LPBF additive manufacturing. This paper has also proposed the possible cracking formation mechanism induced by the added WC particles in the fabricated composites. The following findings were derived from the experimental work.

(1) The LPBF-fabricated composite was observed to have a limited number of pores and microcracks, while only pores were detected in the as-fabricated pure HX. The cracks formed in the composite were distributed along the grain boundaries, indicating that they were intergranular cracks. One possible cracking formation mechanism was that the sub-micrometre WC particle clusters, together with the segregated carbides, caused the grain boundaries to be more susceptible to cracking; when the accumulated thermal residual stress is sufficient to pull apart the grains, hot cracking can occur.

(2) Compared to pure HX, the introduction of $1 \mathrm{wt} . \%$ sub-micrometre WC particles contributed to an approximately $13 \%$ improvement in tensile yield strength on the basis of tensile specimens but without a significant sacrifice in elongation. The significantly increased dislocations were considered to be the primary contributor to the mechanical performance enhancement in the LPBFfabricated composite material. 
Future work will study both theoretically and experimentally the microcracking formation and the corresponding elimination for composites manufactured via the LPBF additive manufacturing process. In addition, while this study has only investigated the effects of $1 \mathrm{wt}$ \% sub-micrometre WC particles on the mechanical behaviours of LPBF-fabricated composites, different levels of WC reinforcement will be investigated in future work. It can also be anticipated that the LPBF-fabricated advanced composites with high-strength and without microcracking defect could be achieved through a careful selection of ceramic reinforcements.

\section{Acknowledgements}

The lead author gratefully appreciates the financial support of the Qilu Young Scholar Programme (Grant No. 31360082063010), Shandong University, China. The authors also wish to thank ASTUTE 2020, a large-scale research programme, funded by the Welsh European Funding Office through the Welsh Government and the participating HE Institutions.

\section{Conflict of interest}

The paper has no conflict of interest in any person or organisation.

\section{Data Availability}

The raw/processed data required to reproduce these findings cannot be shared at this time as the data also forms part of an ongoing study.

\section{References}

1. Yap CY, Chua CK, Dong ZL, et al (2015) Review of selective laser melting: Materials and applications. Appl. Phys. Rev. 2:041101

2. Lewandowski JJ, Seifi M (2016) Metal Additive Manufacturing: A Review of Mechanical Properties. Annu Rev Mater Res 46:151-186. https://doi.org/10.1146/annurev-matsci-070115032024

3. Han Q, Gu Y, Setchi R, et al (2019) Additive manufacturing of high-strength crack-free Nibased Hastelloy X superalloy. Addit Manuf 30:100919. https://doi.org/10.1016/j.addma.2019.100919

4. Attallah MM, Jennings R, Wang X, Carter LN (2016) Additive manufacturing of Ni-based superalloys: The outstanding issues. MRS Bull. 41:758-764

5. Hinojos A, Mireles J, Reichardt A, et al (2016) Joining of Inconel 718 and 316 Stainless Steel using electron beam melting additive manufacturing technology. Mater Des 94:17-27. https://doi.org/10.1016/j.matdes.2016.01.041

6. Han Q, Mertens R, Montero-Sistiaga M, et al (2018) Laser powder bed fusion of Hastelloy X: effects of hot isostatic pressing and the hot cracking mechanism. Mater Sci Eng A 732:228239. https://doi.org/https://doi.org/10.1016/j.msea.2018.07.008 
7. Harrison NJ, Todd I, Mumtaz K (2015) Reduction of micro-cracking in nickel superalloys processed by Selective Laser Melting: A fundamental alloy design approach. Acta Mater 94:59-68. https://doi.org/10.1016/j.actamat.2015.04.035

8. Miracle DB (2005) Metal matrix composites - From science to technological significance. Compos Sci Technol 65:2526-2540. https://doi.org/10.1016/j.compscitech.2005.05.027

9. Singh N, Singh R, Ahuja IPS, et al (2019) Metal matrix composite from recycled materials by using additive manufacturing assisted investment casting. Compos Struct 207:129-135. https://doi.org/10.1016/j.compstruct.2018.09.072

10. Han Q, Geng Y, Setchi R, et al (2017) Macro and nanoscale wear behaviour of Al-Al2O3 nanocomposites fabricated by selective laser melting. Compos Part B Eng 127:26-35. https://doi.org/10.1016/j.compositesb.2017.06.026

11. Kang N, Ma W, Heraud L, et al (2018) Selective laser melting of tungsten carbide reinforced maraging steel composite. Addit Manuf 22:104-110. https://doi.org/10.1016/j.addma.2018.04.031

12. Gu D, Ma J, Chen $\mathrm{H}$, et al (2018) Laser additive manufactured WC reinforced Fe-based composites with gradient reinforcement/matrix interface and enhanced performance. Compos Struct 192:387-396. https://doi.org/10.1016/j.compstruct.2018.03.008

13. Han Q, Gu Y, Wang L, et al (2020) Effects of TiC content on microstructure and mechanical properties of nickel-based hastelloy $X$ nanocomposites manufactured by selective laser melting. Mater Sci Eng A 140008. https://doi.org/https://doi.org/10.1016/j.msea.2020.140008

14. Gu D, Zhang H, Dai D, et al (2019) Laser additive manufacturing of nano-TiC reinforced Nibased nanocomposites with tailored microstructure and performance. Compos Part B Eng 163:585-597. https://doi.org/10.1016/j.compositesb.2018.12.146

15. Zhang H, Gu D, Xi L, et al (2019) Anisotropic corrosion resistance of TiC reinforced Ni-based composites fabricated by selective laser melting. J Mater Sci Technol 35:1128-1136. https://doi.org/10.1016/j.jmst.2018.12.020

16. Wang P, Zhang B, Tan CC, et al (2016) Microstructural characteristics and mechanical properties of carbon nanotube reinforced Inconel 625 parts fabricated by selective laser melting. Mater Des 112:290-299. https://doi.org/10.1016/j.matdes.2016.09.080

17. Rong T, Gu D, Shi Q, et al (2016) Effects of tailored gradient interface on wear properties of WC/Inconel 718 composites using selective laser melting. Surf Coatings Technol 307:418427. https://doi.org/10.1016/j.surfcoat.2016.09.011

18. Nguyen QB, Zhu Z, Chua BW, et al (2018) Development of WC-Inconel composites using selective laser melting. Arch Civ Mech Eng 184:1410-1420.

https://doi.org/10.1016/j.acme.2018.05.001

19. Zhao S, Shen X, Yang J, et al (2018) Densification behavior and mechanical properties of nanocrystalline $\mathrm{TiC}$ reinforced $316 \mathrm{~L}$ stainless steel composite parts fabricated by selective laser melting. Opt Laser Technol 103:239-250. https://doi.org/10.1016/j.optlastec.2018.01.005

20. Wu H, Liu W, He R, et al (2017) Fabrication of dense zirconia-toughened alumina ceramics through a stereolithography-based additive manufacturing. Ceram Int 43:968-972. https://doi.org/10.1016/j.ceramint.2016.10.027

21. Karthik GM, Panikar S, Ram GDJ, Kottada RS (2017) Additive manufacturing of an aluminum matrix composite reinforced with nanocrystalline high-entropy alloy particles. Mater Sci Eng A 679:193-203. https://doi.org/10.1016/j.msea.2016.10.038

22. Deshpande PK, Li JH, Lin RY (2006) Infrared processed Cu composites reinforced with WC particles. Mater Sci Eng A 429:58-65. https://doi.org/10.1016/j.msea.2006.04.124

23. Wang L, Shi JL, Hua Z Le, et al (2001) The influence of addition of WC particles on mechanical properties of alumina-matrix composite. Mater Lett 50:179-182.

https://doi.org/10.1016/S0167-577X(01)00221-X 
24. Li X, Xiao Z, Yang C, Qu S (2010) Research on binderless tungsten carbide prepared by spark plasma sintering. Appl Mech Mater 37-38:980-984.

https://doi.org/10.4028/www.scientific.net/AMM.37-38.980

25. Han Q, Gu Y, Soe S, et al (2020) Effect of hot cracking on the mechanical properties of Hastelloy $X$ superalloy fabricated by laser powder bed fusion additive manufacturing. Opt Laser Technol 124:105984. https://doi.org/10.1016/j.optlastec.2019.105984

26. Han Q, Setchi R, Lacan F, et al (2017) Selective laser melting of advanced Al-Al2O3 nanocomposites: Simulation, microstructure and mechanical properties. Mater Sci Eng A 698:162-173. https://doi.org/10.1016/j.msea.2017.05.061

27. Zhou X, Liu X, Zhang D, et al (2015) Balling phenomena in selective laser melted tungsten. J Mater Process Technol 222:33-42. https://doi.org/10.1016/j.jmatprotec.2015.02.032

28. Liu Y, Zhang J, Yang Y, et al (2017) Study on the influence of process parameters on the clearance feature in non-assembly mechanism manufactured by selective laser melting. J Manuf Process 27:98-107. https://doi.org/10.1016/j.jmapro.2017.04.005

29. Khairallah SA, Anderson AT, Rubenchik A, King WE (2016) Laser powder-bed fusion additive manufacturing: Physics of complex melt flow and formation mechanisms of pores, spatter, and denudation zones. Acta Mater 108:36-45

30. Ly S, Rubenchik AM, Khairallah SA, et al (2017) Metal vapor micro-jet controls material redistribution in laser powder bed fusion additive manufacturing. Sci Rep 7:4085. https://doi.org/10.1038/s41598-017-04237-z

31. Taheri Andani M, Dehghani R, Karamooz-Ravari MR, et al (2017) Spatter formation in selective laser melting process using multi-laser technology. Mater Des 131:460-469. https://doi.org/10.1016/j.matdes.2017.06.040

32. Heeling $\mathrm{T}$, Cloots $\mathrm{M}$, Wegener $\mathrm{K}$ (2017) Melt pool simulation for the evaluation of process parameters in selective laser melting. Addit Manuf 14:116-125. https://doi.org/10.1016/j.addma.2017.02.003

33. Louvis E, Fox P, Sutcliffe CJ (2011) Selective laser melting of aluminium components. J Mater Process Technol 211:275-284. https://doi.org/10.1016/j.jmatprotec.2010.09.019

34. Aboulkhair NT, Everitt NM, Ashcroft I, Tuck C (2014) Reducing porosity in AISi10Mg parts processed by selective laser melting. Addit Manuf 1-4:77-86.

https://doi.org/10.1016/j.addma.2014.08.001

35. Leung CLA, Marussi S, Towrie M, et al (2019) The effect of powder oxidation on defect formation in laser additive manufacturing. Acta Mater 166:294-305. https://doi.org/10.1016/j.actamat.2018.12.027

36. Li XP, Ji G, Chen Z, et al (2017) Selective laser melting of nano-TiB2decorated AlSi10Mg alloy with high fracture strength and ductility. Acta Mater 129:183-193. https://doi.org/10.1016/j.actamat.2017.02.062

37. Ang LK, Lau YY, Gilgenbach RM, Spindler HL (1997) Analysis of laser absorption on a rough metal surface. Appl Phys Lett 70:696-698. https://doi.org/10.1063/1.118242

38. Boley CD, Khairallah SA, Rubenchik AM (2015) Calculation of laser absorption by metal powders in additive manufacturing. Appl Opt 54:2477-2482.

https://doi.org/10.1364/ao.54.002477

39. Ma C, Zhao J, Cao C, et al (2016) Fundamental study on laser interactions with nanoparticlesreinforced metals-part II: Effect of nanoparticles on surface tension, viscosity, and laser melting. J Manuf Sci Eng Trans ASME 138:121001. https://doi.org/10.1115/1.4033446

40. Nan CW, Birringer R, Clarke DR, Gleiter H (1997) Effective thermal conductivity of particulate composites with interfacial thermal resistance. J Appl Phys 81:6692-6699. https://doi.org/10.1063/1.365209

41. Prashanth KG, Eckert J (2017) Formation of metastable cellular microstructures in selective laser melted alloys. J Alloys Compd 707:27-34. https://doi.org/10.1016/j.jallcom.2016.12.209 
42. Vora P, Mumtaz K, Todd I, Hopkinson N (2015) AlSi12 in-situ alloy formation and residual stress reduction using anchorless selective laser melting. Addit Manuf 7:12-19. https://doi.org/10.1016/j.addma.2015.06.003

43. Knapp GL, Mukherjee T, Zuback JS, et al (2017) Building blocks for a digital twin of additive manufacturing. Acta Mater 135:390-399. https://doi.org/10.1016/j.actamat.2017.06.039

44. Aucott $\mathrm{L}$, Dong $\mathrm{H}$, Mirihanage $\mathrm{W}$, et al (2018) Revealing internal flow behaviour in arc welding and additive manufacturing of metals. Nat Commun 9:5414. https://doi.org/10.1038/s41467018-07900-9

45. Sanaty-Zadeh A (2012) Comparison between current models for the strength of particulatereinforced metal matrix nanocomposites with emphasis on consideration of Hall-Petch effect. Mater Sci Eng A 531:112-118. https://doi.org/10.1016/j.msea.2011.10.043

46. Yu WH, Sing SL, Chua CK, et al (2019) Particle-reinforced metal matrix nanocomposites fabricated by selective laser melting: A state of the art review. Prog Mater Sci 104:330-379. https://doi.org/10.1016/j.pmatsci.2019.04.006

47. Zhang D, Niu W, Cao X, Liu Z (2015) Effect of standard heat treatment on the microstructure and mechanical properties of selective laser melting manufactured Inconel 718 superalloy. Mater Sci Eng A 644:32-40. https://doi.org/10.1016/j.msea.2015.06.021

48. Chlebus E, Gruber K, Kuźnicka B, et al (2015) Effect of heat treatment on the microstructure and mechanical properties of Inconel 718 processed by selective laser melting. Mater Sci Eng A 639:647-655. https://doi.org/10.1016/j.msea.2015.05.035

49. Trosch T, Strößner J, Völkl R, Glatzel U (2016) Microstructure and mechanical properties of selective laser melted Inconel 718 compared to forging and casting. Mater Lett 164:428-431. https://doi.org/10.1016/j.matlet.2015.10.136

50. Salarian M, Asgari H, Vlasea M (2020) Pore space characteristics and corresponding effect on tensile properties of Inconel 625 fabricated via laser powder bed fusion. Mater Sci Eng A 769:138525. https://doi.org/10.1016/j.msea.2019.138525

51. Bramfitt BL (1970) The effect of carbide and nitride additions on the heterogeneous nucleation behavior of liquid iron. Metall Trans 1:1987-1995. https://doi.org/10.1007/BF02642799

52. Marchese G, Bassini E, Aversa A, et al (2019) Microstructural evolution of post-processed Hastelloy $X$ alloy fabricated by laser powder bed fusion. Materials (Basel) 12:486.

https://doi.org/10.3390/ma12030486

53. Jinoop AN, Denny J, Paul CP, et al (2019) Effect of post heat-treatment on the microstructure and mechanical properties of Hastelloy-X structures manufactured by laser based Directed Energy Deposition. J Alloys Compd 797:399-412.

https://doi.org/10.1016/j.jallcom.2019.05.050 